\title{
On the Mechanism of Oxidation of Non-Phenolic Lignin Model Compounds by the Laccase-ABTS Couple
}

\author{
By Andreas Muheim ${ }^{1}$, Armin Fiechter ${ }^{1}$, Patricia J. Harvey ${ }^{2}$ and Hans E. Schoemaker ${ }^{3}$ \\ ${ }^{1}$ Eidgenössische Technische Hochschule Zürich, Institut für Biotechnologie, ETH-Hönggerberg, \\ CH-8093 Zürich, Switzerland \\ ${ }^{2}$ Imperial College of Science, Technology and Medicine, Department of Biology, Prince Consort Road, \\ London SW7 2BB, United Kingdom \\ ${ }^{3}$ DSM Research, Bio-organic Chemistry Section, P.O. Box 18, NL-6160 MD Geleen, The Netherlands
}

\section{Keywords}

Laccase-ABTS

Laccase-syringaldehyde

Lignin peroxidase

Veratryl alcohol

Radical cation

H-atom abstraction

Lignin degradation

\begin{abstract}
Summary
Oxidation of veratryl alcohol by laccase in the presence of ABTS (2,2'azino-bis(3-ethylbenzthiazoline-6sulphonic acid) yields veratraldehyde, but differs to the reaction catalysed by lignin peroxidase (LiP) because ring-opened products and quinones associated with the reactivity of radical cation intermediates are not formed. The laccase-ABTS couple is also unable to oxidise 1,4-dimethoxybenzene to benzoquinone. Similar results were obtained using horseradish peroxidase (HRP) and ABTS with $\mathrm{H}_{2} \mathrm{O}_{2}$ as oxidant. These data favour the view that the mechanism of the ABTS-coupled reaction does not involve radical cation formation and that the reactivity of laccase-ABTS is not equivalent to that of LiP. Similarly, no evidence for radical cation formation could be obtained when syringaldehyde was substituted for ABTS. It is suggested that the reactivity observed toward non-phenolic lignin model compounds with these enzyme-coupled systems involves a hydrogen atom abstraction mechanism. The importance of oxidation via hydrogen atom abstraction in lignin degradation remains to be elucidated.
\end{abstract}

\section{Introduction}

White-rot fungi are potent lignin degrading microorganisms, producing lignin peroxidases (LiP), manganese-dependent peroxidases (MnP) (Gold et al. 1989) and laccases in the course of extracellular lignin degradation (Higuchi 1990). The actual mechanism of these enzymes and their role in the process of lignin biodegradation is still under active investigation (Schoemaker and Leisola 1990). Whereas both MnP and laccase are limited to oxidising phenolic compounds, LiP is remarkable in its ability to oxidise nonphenolic lignin model substructures as well. In recent years, much insight has been gained in the mechanism of LiP-catalysis (for a review, see Schoemaker 1990). One-electron oxidation of electron rich (e.g. methoxylated) aromatic systems by LiP to form radical cations (Kersten et al. 1985) can result in a number of ensuing reactions, like $\mathrm{C}_{\alpha}$-oxidation, $\mathrm{C}_{\alpha}-\mathrm{C}_{\beta}$-cleavage and $(\beta-\mathrm{O}-4)$ ether bond cleavage (Schoemaker et al. 1985). The latter two examples represent depolymerisation reactions. This ability to oxidise non-phenolic systems makes LiP a more effective delignifying agent than the phenol-oxidising enzymes, MnP or laccase.

Recently, reports have appeared on the oxidation of non-phenolic substrates by laccase in the presence of catalytic amounts of ABTS or of syringaldehyde (Bourbonnais and Paice 1990; Kawai et al. 1989). This has led to the suggestion that laccase could play a role in depolymerisation "equally as significant as that of LiP" (Bourbonnais and Paice 1990).

In this paper we have compared the mechanism of catalysis of LiP with that of the laccase-ABTS couple. We show that the oxidation of non-phenolic compounds by the laccase-ABTS couple and the laccasesyringaldehyde couple, unlike the mechanism of oxidation by LiP, does not proceed via radical cationic intermediates.

The significance of laccase in the process of lignin biodegradation remains to be established.

\section{Material and Methods}

\section{Enzyme preparation}

Laccase was prepared according to Fahreus and Reinhammer (1967) except that it was concentrated from the extracellular medium by batch ion-exchange chromatography (DEAE-cellulose). Laccase was also supplied as a kind gift of Dr. M. Leisola from Cultor Ltd, Finland. The enzyme activity was determined spectrophotometrically using ABTS as substrate. $1 \mathrm{U}$ was defined as the amount of enzyme which oxidises $1 \mu \mathrm{mol}$ ABTS per min.

LiP was prepared and purified according to Glumoff et al. (1990). $1 \mathrm{U}$ oxidiscs $1 \mu \mathrm{mol}$ veratryl alcohol per min. Horscradish peroxidase (HRP) was purchased from Sigma Chemical Co. and the enzyme activity determined as for laccase.

\section{Chemicals}

2,2'-Azino-bis(3-ethylbenzthiazoline-6-sulphonic acid) (ABTS) and 4-hydroxy-3,5-dimethoxybenzaldchyde (syringaldchyde) were 
purchased from Sigma, USA. Veratryl alcohol, 3,4-dimethoxyphenylacetic acid (homoveratric acid) and manganese (III) acetate wcre obtained from Fluka, Switzerland. 1,4-Dimethoxybenzenc was purchased from Aldrich Chemical Co. 1-(3,4-Dimethoxyphenyl)-2-phenylethanol ( $\alpha$-benzyl veratryl alcohol) was synthesized as described earlier (Muheim et al. 1990).

\section{Enzymatic reactions}

All the experiments were carried out at room temperature. In the case of oxygen flushing the reaction mixture was flushed $15 \mathrm{~min}$ prior and during reactions.

The normal reaction mixture contained $0.8 \mathrm{mM}$ mediator, $3 \mathrm{mM}$ test substrate, $0.1 \mathrm{M}$ sodium acetate, $\mathrm{pH} 3.5$ and $0.1 \mathrm{U} \mathrm{ml}^{-1}$ laccase. Alternatively, $0.1 \mathrm{M}$ sodium tartrate, $\mathrm{pH} 3.0$ or acetate buffer $\mathrm{pH}$ 4.0 or 5.0 were used. The concentrations were reported to be optimal (Bourbonnais and Paice 1990). Reactions with HRP contained either $0.2 \mathrm{U} \mathrm{ml}^{-1}$ or $0.4 \mathrm{U} \mathrm{ml}^{-1}$ enzyme with 0.45 or $1.0 \mathrm{mM} \mathrm{H}_{2} \mathrm{O}_{2}$, respectively. Reactions with $\mathrm{LiP}$ used $0.15 \mathrm{U} \mathrm{ml}^{-1}$ enzyme and 0.45 $\mathrm{mM} \mathrm{H} \mathrm{H}_{2} \mathrm{O}_{2}$. As mediators, ABTS or syringaldehyde were tested. As substrates, veratryl alcohol, dimethoxybenzene, homoveratric acid and $\alpha$-benzyl veratryl alcohol were used. The latter one was used at lower concentrations of $0.1-0.4 \mathrm{mM}$ because of its low solubility.

The reactions were normally analysed after $24 \mathrm{~h}$ by HPLC. Products from the reaction mixture containing the dimeric compound, $\alpha$-benzyl veratryl alcohol, were extracted with methylene chloride. The extracts were dried under nitrogen and analysed. Samples from other reactions were injected directly after filtration through a 0.45 $\mu \mathrm{m}$ pore size filter.

Reversed phase HPLC was performed using a $\mathrm{C}_{18}$ column, eluted isocratically with either $50 \%$ acetonitrile or $40 \%$ methanol or with a gradient (Schmidt et al. 1989) with a flow rate of $1.0 \mathrm{ml} \mathrm{min}^{-1}$.

\section{Results and Discussion}

\section{ABTS as a mediator}

Laccase, a phenoloxidase produced by various whiterot fungi, will oxidise similar substrates as MnP and HRP (Gold et al. 1989; Higuchi 1990). However, in contrast to $\mathrm{LiP}$, laccases are not able to oxidise non-phenolics with a higher electropotential than $\mathrm{E}_{1 / 2}=1.06 \mathrm{~V}$ (versus a saturated calomel electrode) (Kersten et al. 1990). Veratryl alcohol, a common assay substrate for LiP (Tien and Kirk 1984), has a electropotential of $1.22 \mathrm{~V}$ and is not oxidised by laccase (Fawer et al. 1991). The LiP-catalysed reaction yields veratraldehyde 2 together with variable amounts of quinones 3 and 4 and ring opened products 5 , resulting from attack of water and oxygen or active oxygen species on the initially formed radical cation of veratryl alcohol (Haemmerli et al. 1987; Schmidt et al. 1989).

In confirmation of the report by Bourbonnais and Paice (1990), it was found that laccase alone was unable to oxidise veratryl alcohol, but in the presence of ABTS, a common peroxidase and phenoloxidase assay agent, veratryl alcohol 1 was oxidised quantitatively to veratraldehyde 2 (see Fig. 1). However, in the reaction catalysed by laccase-ABTS, we found neither quinones nor ring-opened products. The same results were obtained when the reaction mixture was flushed with oxygen or when the reaction was catalysed by $\mathrm{HRP}$, which needs $\mathrm{H}_{2} \mathrm{O}_{2}$ for regeneration.

Oxidation of ABTS by either laccase or HRP proceeds rapidly and is completed within a few minutes. However, Figure 2 shows that the coupled oxidation of veratryl alcohol took place over several hours, with the extent of conversion dependent on the level of enzyme supplied. When ABTS $^{+\cdot}$ was isolated from laccase by filtration and mixed with veratryl alcohol, veratryl alcohol was not oxidised to a major extent. However, addition of laccase back to the mixture of isolated $\mathrm{ABTS}^{+\cdot}$ and veratryl alcohol now resulted in the significant formation of veratraldehyde. When 3 $\mathrm{mM}$ of $\mathrm{Mn}$ (III)-acetate was added to a mixture of ABTS (0.8 mM) and veratryl alcohol (3 mM), an immediate formation of the $\mathrm{ABTS}^{+\cdot}$ - radical cation was observed, but only a minor amount of veratraldehyde could be detected after several days of incubation. Figure 3 shows that the $\mathrm{pH}$ optimum of the reaction was $\mathrm{pH} \mathrm{3,} \mathrm{similar} \mathrm{to} \mathrm{that} \mathrm{of} \mathrm{the} \mathrm{LiP-catalysed} \mathrm{oxida-}$ tion of veratryl alcohol, but dissimilar to the normal $\mathrm{pH}$ optimum for laccase-catalysed reactions $(\mathrm{pH} 5)$.

In Figure 4 the dependence of the rate of veratryl alcohol oxidation on the concentration of the enzyme is shown, indicating that it is indeed an enzyme catalysed reaction. However, relatively high amounts of enzyme are needed for an appreciable rate and yield.

The oxidation of veratryl alcohol by LiP has been described in terms of the enzymic production of radical cations followed by further non-enzymic reactions (Harvey et al. 1985; Gilardi et al. 1990). However, oxidation of veratryl alcohol can also be envisaged in terms of the abstraction of a $\mathrm{C}_{\alpha}$-hydrogen atom to form a hydroxy-substituted 3,4-dimethoxybenzyl radical which is further oxidised directly to veratraldehyde. The data obtained so far for the ABTScoupled enzyme systems strongly suggested that oxidation of veratryl alcohol did not involve formation of the veratryl alcohol radical cation intermediate and therefore differed to the mechanism used by LiP. To test this hypothesis, experiments were designed baséd on the oxidation of 1,4-dimethoxybenzene 6. Oxidation of this compound by LiP has been shown to proceed via an ESR-detectable radical cationic intermediate to form benzoquinone 7 (Kersten et al. 1985). Using the laccase-ABTS mediated reaction, dimethoxybenzene was not oxidised. This result supported the view that oxidation of veratryl alcohol by the ABTS-coupled enzyme systems does not involve a radical cation intermediate. However, when the $\mathrm{LiP}$ catalysed oxidation of 1,4-dimethoxybenzene was studied in the presence of ABTS, although ABTS was oxidised, benzoquinone formation was not observed 
<smiles>COc1ccc(CO)cc1OC</smiles>

1<smiles>COc1ccc(CO)cc1OC</smiles><smiles>COc1ccc(CO)cc1OC</smiles>

1

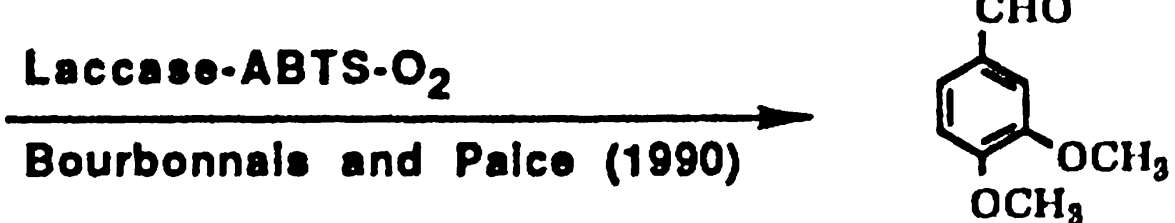

2

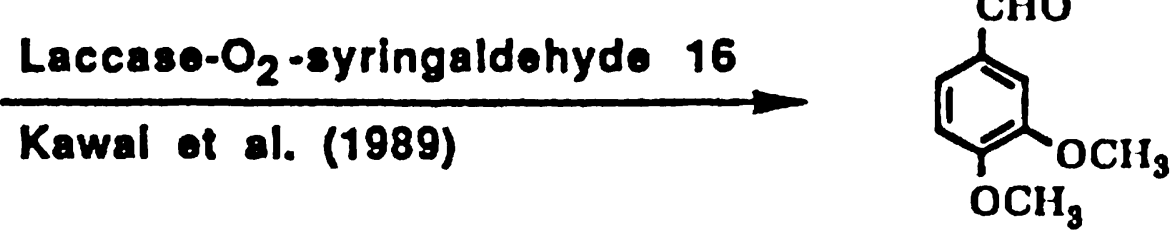

2<smiles>COc1ccc(C=O)cc1OC</smiles><smiles>COC1CC(=O)C(CO)CC1=O</smiles>

2

3

Schmidt of al. (1989)<smiles>COc1ccc(OC)cc1</smiles>

6<smiles>COc1ccc(OC)cc1</smiles>

6<smiles>COc1ccc(C(O)Cc2ccccc2)cc1OC</smiles>

no reaction

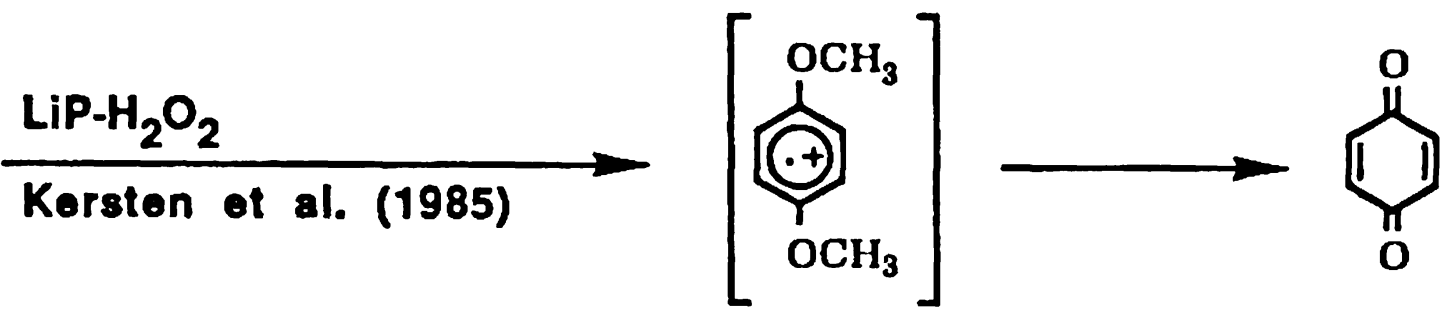

7

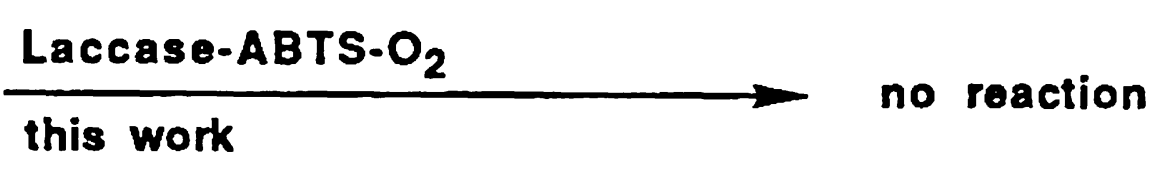<smiles>CCOC(C)C(C)C</smiles><smiles>C#CCOCCOCCOc1cc(C=O)ccc1OC</smiles>

2

Fig. 1a. Structures of (non)-phenolic lignin model compounds and their degradation products.

either. As a control, the LiP catalysed oxidation of veratryl alcohol in the presence of ABTS was therefore studied. Although veratraldehyde was formed, the yield was low compared to the level of $\mathrm{H}_{2} \mathrm{O}_{2}$ supplied and veratraldehyde was now the sole product; neither quinones $(3,4)$ nor ring-opened products 5 could be detected. These data may be explained by supposing that, similar to the oxidation of phenolic compounds (Harvey and Palmer 1990), ABTS is preferentially oxidised by LiP compared to veratryl alcohol or dimethoxybenzene, but results in the formation of the catalytically less reactive redox state known as compound III (Schoemaker 1990). Products are observed in the case of veratryl alcohol by reaction with $\mathrm{ABTS}^{+}$. or reactive reagents derived thereof, but not in the case of dimethoxybenzene, similar to the laccaseABTS couple described.

Radical cation formation is an essential condition for important LiP-catalysed depolymerisation reactions like $\mathrm{C}_{\alpha}-\mathrm{C}_{\beta}$-cleavage and $\beta-\mathrm{O}-4$ ether bond cleavage (Muheim et al. 1990). The inability of the laccaseABTS couple to catalyse benzoquinone formation 


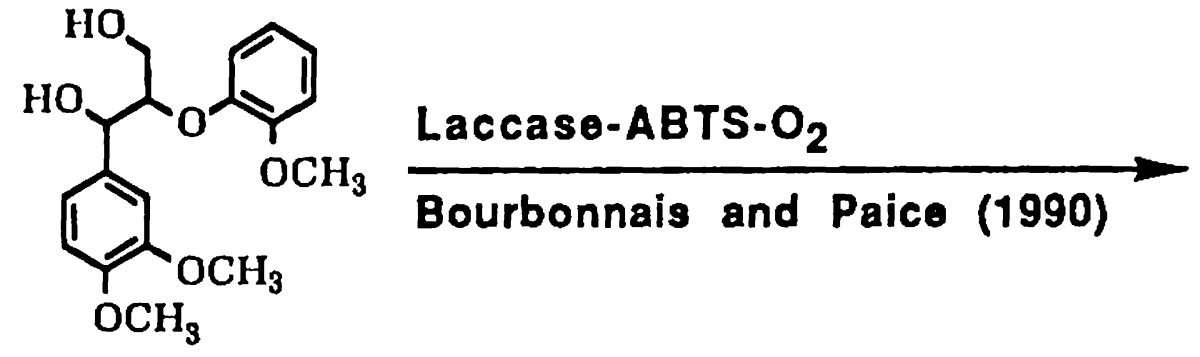

9<smiles>COc1ccc(C(O)c2ccccc2)cc1OC</smiles>

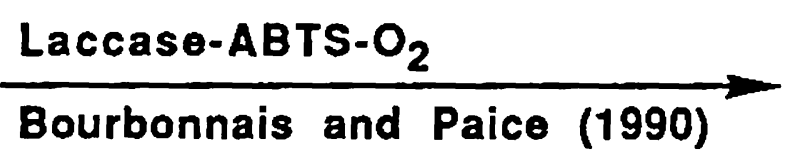

11<smiles>COc1ccc(CC(=O)O)cc1OC</smiles>

13<smiles>COc1ccc(C(=O)C(CO)Oc2ccccc2OC)cc1OC</smiles>

10<smiles>COc1cc(C(O)C(CO)c2cc(OC)c(OC)c(OC)c2)cc(OC)c1OC</smiles>

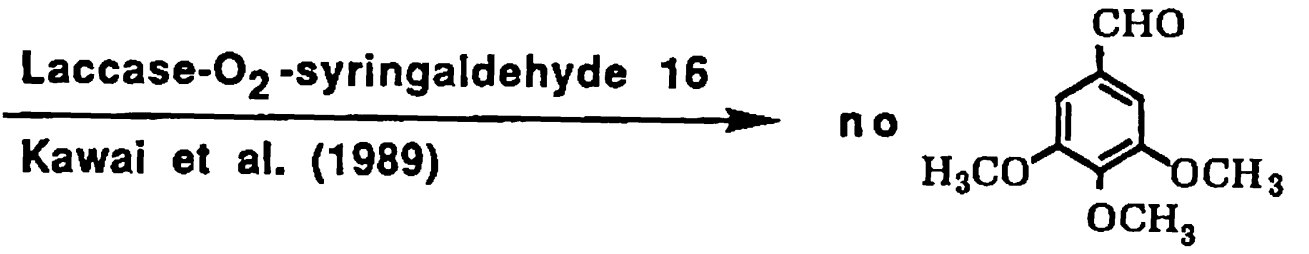

15

14<smiles>COc1cc(C=O)cc(OC)c1O</smiles>

16

Fig. 1b. Structures of (non)-phenolic lignin model compounds and their degradation products.

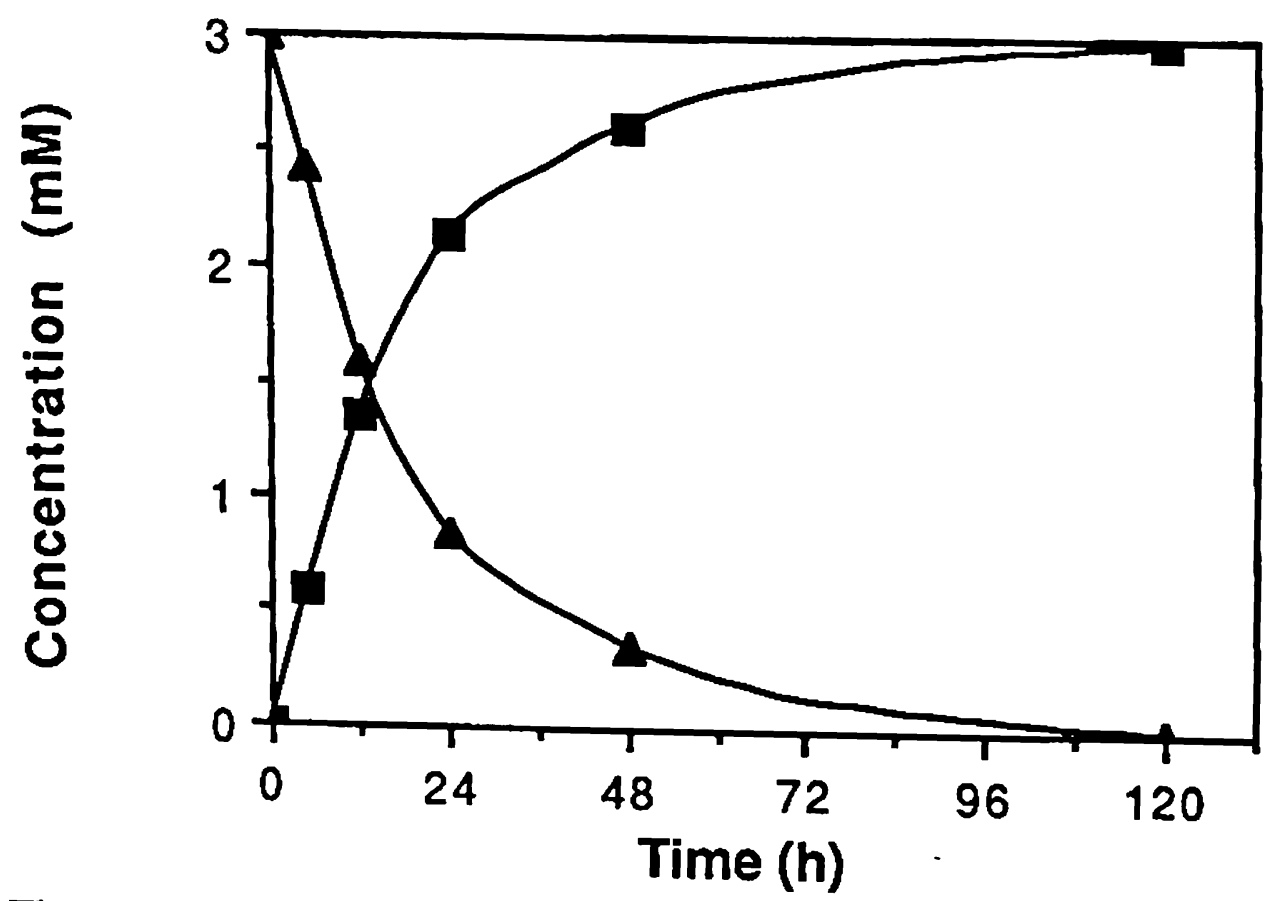

Fig. 2. Oxidation of veratryl alcohol by laccase and ABTS. Note the oxidation of the mediator ABTS to the radical occurs within the first minutes of the reaction. Concentration of $(\mathbf{A})$ veratryl alcohol and $(\boldsymbol{\square})$ veratraldehyde were analysed by HPLC.

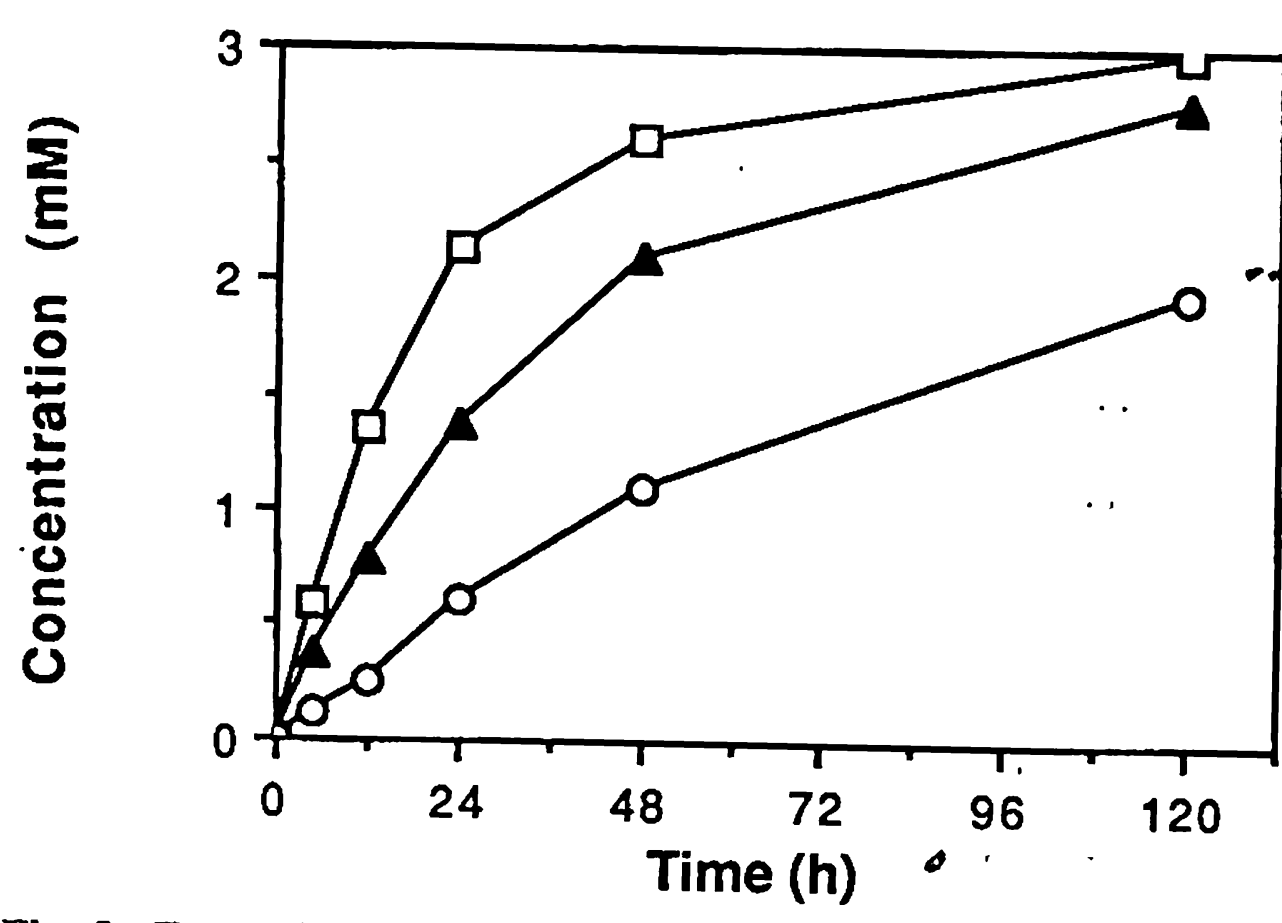

Fig. 3. Formation of veratraldehyde in the oxidation of veratryl alcohol by the laccase-ABTS couple as a function of $\mathrm{pH}$ : (D) $\mathrm{pH} 3$, (A) $\mathrm{pH} 4,(\mathrm{O}) \mathrm{pH} 5$. 


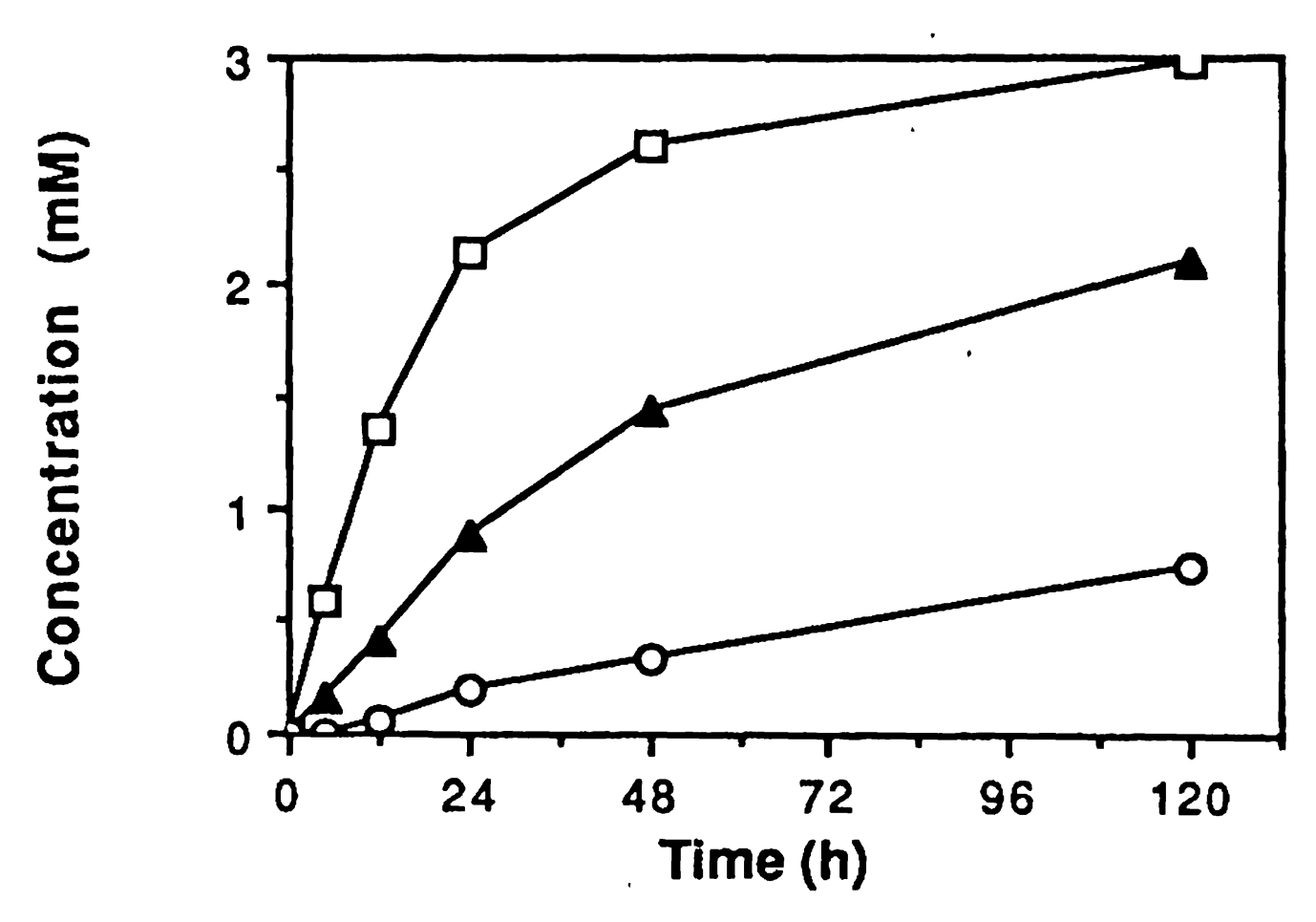

Fig. 4. Enzyme dependance of the mediated oxidation of veratryl alcohol. The concentration of veratraldehyde formed was analysed by HPLC. The laccase concentrations used were ( $\square) 0.1 \mathrm{U} \mathrm{ml}^{-1}$, (A) $0.01 \mathrm{U} \mathrm{ml}^{-1}$, (O) $0.001 \mathrm{U} \mathrm{ml}^{-1}$.

from 1,4-dimethoxybenzene strongly suggested that this system would not catalyse the same bond cleavage reactions as LiP. To test this idea, the oxidation of the dimeric lignin model compound 1-(3,4-dimethoxyphenyl)-2-phenyl-ethane-1-ol 8 ( $\alpha$-benzylveratryl alcohol) was studied. Veratraldehyde was not observed in the ABTS-mediated reaction using a detection limit of less $10 \mathrm{nmol}$, whereas in the LiP catalysed reaction veratraldehyde is formed as a result of $\mathrm{C}_{\alpha}-\mathrm{C}_{\beta}$-cleavage. The laccase-ABTS couple has been reported to mediate the oxidation of a $\beta-\mathrm{O}-4$ lignin model compound, 1-(3,4-dimethoxyphenyl)-2-(2methoxyphenyl)-propane-1,3-diol 9 (Bourbonnais and Paice 1990). In contrast to the oxidation of this compound with LiP, no evidence was obtained for $\beta-\mathrm{O}-4$ ether bond cleavage or $\mathrm{C}_{\alpha}-\mathrm{C}_{\beta}$-cleavage by the laccase-ABTS couple. Instead, only a $\mathrm{C}_{\alpha}$-oxidised product, 1-(3,4-dimethoxyphenyl)-2-(2-methoxyphenyl)-3-hydroxy-1-propanone 10 was isolated, possibly being formed after $\mathrm{C}_{\alpha}$-hydrogen atom abstraction and further oxidation to the ketone.

Bourbonnais and Paice (1990) also found that the laccase-ABTS couple mediated the oxidation of 1-(3,4dimethoxyphenyl)-2-phenylethanediol 11 to form veratraldehyde 2 and benzaldehyde 12 upon $\mathrm{C}_{\alpha}-\mathrm{C}_{\beta}$-cleavage. Using 3,4-dimethoxyphenylacetic acid $\mathbf{1 3}$ (homoveratric acid) we found evidence of $\mathrm{C}_{\alpha}-\mathrm{C}_{\beta}$ cleavage in that homoveratric acid was decarboxylated to form veratryl alcohol and ultimately veratraldehyde as the products. Decarboxylation of this compound has been described as a result of LiPcatalysis involving a radical cationic intermediate (Muheim et al. 1990; Harvey et al. 1986). Since radical cation formation induced by the laccase-ABTS couple appears unlikely, the elucidation of the mechanisms of the oxidation of compounds $\mathbf{1 1}$ and $\mathbf{1 3}$ has to await further investigation.

\section{Syringaldehyde as a mediator}

Apart from ABTS, syringaldehyde $\mathbf{1 6}$ has also been reported to act as a mediator in the laccase-catalysed oxidation of veratryl alcohol (Kawai et al. 1989). However, when this compound was substituted for ABTS in the experiments described above, less than $1 \%$ of veratryl alcohol was oxidised to veratraldehyde. This low conversion was not enough to accurately investigate the possible formation of quinones 3 and 4 and ring opened products 5 . Thus, no direct evidence on the formation of a radical cationic intermediate from veratryl alcohol could be obtained. However, it was reported that the $\beta-1$ dimeric model compound 14 tested (Kawai et al. 1989) was not cleaved to form 3,4,5-trimethoxybenzaldehyde, in contrast to the oxidation of this compound with $\mathrm{LiP}$, indicating that the mechanism for the laccase-syringaldehyde couple does not involve radical cationic intermediates.

\section{Conclusion}

Our results indicate that the laccase-ABTS couple does not have the same reactivity as LiP. It does not lead to radical cation formation, as can be inferred from the results with 1,4-dimethoxybenzene 6 , the $\beta-1$ dimeric model 8 and the $\beta-\mathrm{O}-4$ dimeric model 9. Also the lack of side product formation in the veratryl alcohol oxidation is indicative of a mechanism that does not involve radical cationic intermediates.

Most of the results can be explained assuming a hydrogen atom abstraction mechanism. In the case of veratryl alcohol and the $\beta-1$ and $\beta-O-4$ dimers hydrogen atom abstraction from the $\mathrm{C}_{\alpha}$-position will lead to hydroxy-substituted benzyl radicals, which are subsequently oxidised to the corresponding aldehyde or ketone functionalities. The mechanism of homoveratric acid 13 oxidation and the mechanism by which 1-(3,4-dimethoxyphenyl)-2-phenylethanediol $\mathbf{1 1}$ is cleaved are still not clear at the moment. However, specific cleavage reactions, possibly induced by hydrogen atom abstraction as in the MnP-glutathione system (Wariishi et al. 1989), are clearly possible. The importance of cleavage reactions induced by hydrogen atom abstraction in lignin degradation remains to be elucidated.

\section{References}

Bourbonnais, R. and M. Paice. 1990. Oxidation of non-phenolic substrates: An expanded role for laccase in lignin biodegradation. FEBS Lett. 267, 99-102.

Fahreus, G. and B. Reinhammer. 1967. Large scale production and purification of laccase from cultures of the fungus Polyporus versicolor and some propertics of laccase A. Acta Chcm. Scand. 21, 2367-2378.

Fawer, M., J. Sticrli, S. Cliffe and A. Ficchter. 1991. The characterisation of immobilised lignin peroxidase by flow injection analysis. Biochim. Biophys. Acta 1076, 15-22.

Gilardi, G., P.J. Harvey, A.E.G. Cass and J.M. Palmer. 1990. Rad- 
ical intermediates in veratryl alcohol oxidation by ligninase NMR evidence. Biochim. Biophys. Acta 1041, 129-132.

Glumoff, T., P.J. Harvey, S. Molinari, M. Goble, G. Frank, J.M. Palmer, J.D.G. Smit and M.S.A. Leisola. 1990. Lignin peroxidase from Phanerochaete chrysosporium. Molecular and kinetic characterization of isozymes. Eur. J. Biochem. 187, 515-520.

Gold, M.H., H. Wariishi and K. Valli. 1989. Extracellular peroxidases involved in lignin degradation by the white rot basidiomycete Phanerochaete chrysosporium. In: Biocatalysis in Agricultural Biotechnology (J.R. Whitaker and P.E. Sonnet. Eds.) pp. 127-140 ACS Symposium Series 389, Washington DC.

Haemmerli, S.D., H.E. Schoemaker, H.W.H. Schmidt and M.S.A. Leisola. 1987. Oxidation of veratryl alcohol by the lignin peroxidase of Phanerochaete chrysosporium. FEBS Lett. 220, $149-154$.

Harvey, P.J., H.E. Schoemaker, R.M. Bowen and J.M. Palmer. 1985. Single-electron transfer processes and the reaction mechanism of enzymic degradation of lignin. FEBS Lett. 183, 13-16.

Harvey, P.J., H.E. Schoemaker and J.M. Palmer. 1986. Veratryl alcohol as a mediator and the role of radical cation in lignin degradation by Phanerochaete chrysosporium. FEBS Lett. 195, 242-246.

Harvey, P.J. and J.M. Palmer. 1990. Oxidation of phenolic compounds by ligninase. J. Biotechnol. 13, 169-179.

Higuchi, T. 1990. Lignin biochemistry: Biosynthesis and biodegradation. Wood Sci. Technol. 24, 23-63.

Kawai, S.T. Umezawa and T. Higuchi. 1989. Oxidation of methoxylated benzyl alcohol by Coriolus versicolor in the presence of syringaldehyde. Wood Res. 76, 10-16.
Kersten, P.J., M. Tien, B. Kalyanaraman and T.K. Kirk. 1985. The ligninase of Phanerochaete chrysosporium generates cation radicals from methoxybenzenes. J. Biol. Chem. 260, 2609-2612.

Kersten, P.J., B.Kalyanaraman, K.E. Hammel, B. Reinhammar and T.K. Kirk. 1990. Comparison of lignin peroxidase, horseradish peroxidase and laccase in the oxidation of methoxybenzenes. Biochem. J. 268, 474-480.

Muheim, A., H.E. Schoemaker and M.S.'A. Leisola. 1990. Arylalcohol oxidase and lignin peroxidase from the white-rot fungus Bjerkandera adusta. J. Biotechnol. 13, 159-168.

Schmidt, H.W.H., S.D. Haemmerli, H.E. Schoemaker and M.S.A. Leisola. 1989. Oxidative degradation of 3,4-dimethoxybenzyl alcohol and its methyl ether by the lignin peroxidase of Phanerochaete chrysosporium. Biochemistry 28, 1776-1783.

Schoemaker, H.E., P.J. Harvey, R.M. Bowen and J.M. Palmer. 1985. On the mechanism of enzymatic lignin breakdown. FEBS Lett. 183, 7-12.

Schoemaker, H.E. and M.S.A. Leisola. 1990. Degradation of lignin by Phanerochaete chrysosporium. J. Biotechnol. 13, 101-109.

Schoemaker, H.E. 1990.: On the chemistry of lignin biodegradation. Recl. Trav. Chim. Pays-Bas 109, 255-272.

Tien, M. and T.K. Kirk. 1984. Lignin-degrading enzyme from Phanerochaete chrysosporium: purification, characterization and catalytic properties of a unique $\mathrm{H}_{2} \mathrm{O}_{2}$-requiring oxygenase. Proc. Natl. Acad. Sci. USA. 81, 2280-2284.

Wariishi, H., K. Valli, V. Renganathan and M.H. Gold. 1989.Thiolmediated oxidation of non-phenolic lignin model compounds by manganese peroxidase of Phanerochaete chrysosporium. $\mathrm{J}$. Biol. Chem. 264, 14185-14191. 